\title{
Network reconfiguration and optimal allocation of multiple DG units in radial distribution system
}

\author{
G. Poornachandra Rao ${ }^{1 *}$ and P. Ravi Babu ${ }^{2}$ \\ Research Scholar, Visvesvaraya Technological University, Belagavi, India ${ }^{1}$ \\ Professor, Department of Electrical and Electronics Engineering, Sreenidhi Institute of Science and Technology, \\ Hyderabad, India ${ }^{2}$
}

Received: 05-May-2021; Revised: 23-August-2021; Accepted: 26-August-2021

(C)2021 G. Poornachandra Rao and P. Ravi Babu. This is an open access article distributed under the Creative Commons Attribution (CC BY) License, which permits unrestricted use, distribution, and reproduction in any medium, provided the original work is properly cited.

\begin{abstract}
Network reconfiguration and installation of Distributed Generation (DG) are widely used for loss minimization and betterment of the voltage profile. The major identifiers in the DG installation are the position and size of the DG. In this research, network reconfiguration and DG installation are solved using a hybrid Binary Particle Swarm Optimization with Ant Lion Optimizer (BPSO-ALO). Four different cases of the system with only reconfiguration, the system with the installation of a single DG unit, the system with reconfiguration and a single DG unit, and the system with reconfiguration and multiple DG units are considered to assess the performance of the hybrid BPSO-ALO method. The hybrid BPSO-ALO approach was tested on an IEEE 33-bus test system. The results were compared to those of the Modified Sequential Switch Opening (MSSO), Ant Lion Optimizer (ALO) Algorithm, Strength Pareto Evolutionary Algorithm (SPEA), and the Adaptive Cuckoo Search Algorithm (ACSA). By applying the hybrid BPSO-ALO approach, the power loss in the IEEE 33 test bus system was decreased to $45.71 \mathrm{~kW}$ for case $\mathrm{IV}$, which is smaller than MSSO $57.7 \mathrm{~kW}$, ALO $58.34 \mathrm{~kW}, \mathrm{SPEA} 58.55 \mathrm{~kW}$, and ACSA $53.21 \mathrm{~kW}$.
\end{abstract}

\section{Keywords}

Ant lion optimizer, Binary particle swarm optimization, Distributed generation, Network reconfiguration, Power loss, Radial distribution system.

\section{Introduction}

The most common methods used to minimize losses and enhance the voltage profile in distribution systems are network reconfiguration and Distributed Generation ((DG) installation). The reconfiguration of the network involves modifying the distribution system structure by adjusting the open/close state of ties and sectionalizing switches. DG is power generation in a distributed system with renewable or low-carbon emission sources [1, 2]. An Ant Lion Optimizer (ALO) methodology is used to determine optimal network reconfiguration while simultaneously allocating and sizing DGs to decrease power loss and intensify voltage stability [3]. A reconfiguration technique based on the Moth Swarm Algorithm has been proposed to subside power losses [4].

\footnotetext{
*Author for correspondence
}

The reconfiguration of the radial distribution network is used to minimize the losses and intensify the voltage profile while satisfying the operating constraints [5]. The discrete-improved binary particle swarm optimization algorithm is used for the reconfiguration of distribution systems to minimize power losses and enhance the profile of voltage [6]. Network reconfiguration improves load balancing and reduces apparent losses [7]. Feeder reconfiguration with distributed generation unit allocation can lessen power losses [8], enhance the voltage profile and system reliability [9] in the distribution network. Simultaneous reconfiguration with the integration of the distributed generation unit reduces losses and enhances the stability and reliability of the system [10]. The distribution systems are organized into a radial structure and switches in the network are either in open or closed modes that are considered as the network's strategic points for reconfiguration [11]. The placement of DG plays a significant role in distribution system management [12]. 
The improvement in reliability in radial distribution systems can be achieved by reconfiguration by allocating DG units [13].

Photovoltaic cells and wind energy conversion systems are widely used as alternative energy resources to solve problems with existing energy resources and environmental concerns [14]. DG is a small power production system that can be directly connected with the distribution network that can produce power from renewable energy resources [15]. To reduce the consumption of fossil fuels in electricity production, renewable energy sources based on DGs have been developed [16], which help to minimize power loss, provide continuous power supply for load demand, and avoid toxic carbon emissions [17]. The optimal placement of DG aids in the reduction of power losses and the strengthening of the voltage profile in distribution networks [18]. The DG helps to support and attain real power along with reactive power compensation, and it is responsible for efficient power and energy reliability $[19,20]$.

The hybrid Binary Particle Swarm Optimization with Ant Lion Optimizer (BPSO-ALO) algorithm is introduced in this research to subside power loss and boost the voltage profile by simultaneous network configuration with DG placement in the distribution system. The BPSO technique is used for finding an optimum network reconfiguration which improves the voltage profile and reduces power loss. The optimal DG size is achieved by ALO. That leads to minimizing power loss. The optimal DG location is obtained by using the Loss Sensitivity Factor (LSF). The proposed method shows better performance than the conventional methods. The test case IV (i.e., reconfiguration with multiple DG units) demonstrates that, concerning the base configuration, the results of the test case IV are more efficient in reducing power loss and having a refined voltage profile.

In this work, the hybrid BPSO-ALO algorithm is adapted:

- To attain optimum network reconfiguration of distribution systems

- To attain optimum DG sizing and location in distribution systems

- To reduce power losses in the distribution system

- To improve the voltage profile

\section{Literature review}

This section provides a literature survey of the recent techniques related to reconfiguration and placement of DG units in radial distribution systems.

1020
Ali et al. [1] developed an improved Decompositionbased Evolutionary Algorithm (I-DBEA) to choose the optimal number, capacity, and location of DGs. The appropriate location and position of DG are effectively solved by the I-DBEA method. The suggested method is independent of the penalty factor, which results in better enhancement of the voltage profile. However, concurrent network reconfiguration and DG placement are not taken into account. To decrease power loss in distribution networks by network reconfiguration with and without distributed generation integration.

Vai et al. [2] created the Modified Sequential Switch Opening and Exchange (MSSOE) approach. To reduce the search space in the iteration phase, the fundamental loop has been introduced for the MSSOE technique. MSSOE will notice whether any switches in each phase of a search are removed in the same loop from the selected tie-switch to prevent them from opening during the next iteration. The difficulty of allocating and sizing distributed generations for the suggested reconfiguration process, including their maximum penetration, however, is not considered.

Vijayalakshmi and Gayathri [3] developed an ALO methodology to determine optimal network reconfiguration while simultaneously allocating and sizing DGs to reduce power loss and enhance voltage stability. When compared to existing methods, the proposed method efficiently reduces power loss and obtains the best voltage stability index and voltage profile. However, the case of reconfiguration with the installation of a single DG unit is not considered.

Nguyen and Long [4] developed a network reconfiguration technique based on the moth swarm algorithm to reduce power losses in electrical distribution systems. The Moth Swarm Algorithm (MSA) is a new hypothesis inspired by a moths' dark navigational technique for locating food sources. For the optimal power flow problem, MSA has shown advantages over Particle Swarm Optimization (PSO) and other methods. The application of MSA to other power system issues, such as the network Reconfiguration problem, is still a concern.

Tiwari and Babu [5] presented the Whale Optimization Algorithm (WOA) to reconfigure the network. The WOA was largely inspired by the intelligent hunting behaviour of humpback whales. The WOA was used to enhance the voltage profile and reduce the active power loss in the network. Moreover, this WOA was analysed on two different bus systems, 
such as the IEEE standard 69 and 119 bus systems, that were used to validate the WOA algorithm's efficiency. The exploration of the WOA was not effective during the searching process.

Kamble et al. [6] presented a discrete improved binary PSO algorithm for the reconfiguration of a network to minimize power loss and enhance the profile of voltage. The algorithm is applied to 16-bus systems, 33 and 69 bus systems under various loading conditions. However, simultaneous network reconfiguration and DG placement are not taken into account.

Babu et al. [7] developed an Artificial Ant Colony Optimization (AACO) technique to solve distribution system reconfiguration with the objectives of improving load balance, service restoration, and apparent power loss reduction. The effectiveness of the AACO method was demonstrated on the IEEE three-feeder system for load balance, the IEEE fourfeeder system for service restoration, and the IEEE 33 bus system for apparent power loss minimization. The system failed to maintain the optimal load balance when the load balancing index was high.

PSO was presented by Prakash and Lakshminarayana [21] to achieve the placement of multiple DGs in a distribution system that is used to minimize power loss. This PSO algorithm mainly considered the voltage profile and power loss, but it failed to consider the issues related to cost and load restoration. Furthermore, in high-dimensional space, this PSO easily falls into the local optimum and has a very low convergence rate.

Singh and Gyanish [22] developed the DGs in different sizes to analyse the voltage magnitude, cost, and energy loss in the distribution system. In the distribution system, the phantom power loss and true power loss were minimized using the load flow method that also reduced the objective function. The reactive and real power losses were also minimized along with the increasing power factor of 0.80 to 0.99 . Moreover, the reactive and real power losses were also minimized by increasing the DG size. However, at a certain DG size, power losses increase.

Sanjay et al. [23] presented the Hybrid Grey Wolf Optimizer (HGWO) to create a solution for discrete and non-convex problems. This HGWO algorithm was compared with other optimal results from the exhaustive search algorithm. Moreover, the optimal DG placement using the HGWO algorithm improved the voltage profile and minimized power loss. The major limitation of the Grey Wolf Optimizer was its low capability of handling the difficulties of a multimodal search landscape.

Hamida et al. [24] developed renewable DG integration with reconfiguration. The optimal solution for the Pareto set was selected using the Strength Pareto Evolutionary Algorithm (SPEA). The investigation into DG integration and reconfiguration showed that the SPEA provided better accuracy and efficiency while identifying the optimal network configuration for the network manager. But, the SPEA method doesn't consider the weighted sum of objective functions, which causes unequal optimization in objectives.

Nguyen et al. [25] presented the Adaptive Cuckoo Search Algorithm (ACSA) to obtain distributed generation allocation and optimal network reconfiguration in the distribution network. This adequate network configuration based on ACSA is used to improve power loss and voltage stability. The ACSA is used to identify the search space that is used to minimize ineffective network configurations. Moreover, this ACSA is also used to validate the radial constraint of each configuration in the distribution network. However, in some scenarios, the performance of ACSA was lower when compared with other algorithms.

Concurrent network reconfiguration and DG placement are not taken into account in $[1,3,6]$. The difficulty of allocating and sizing distributed generations for the suggested reconfiguration process, including their maximum penetration, is not considered in [2]. The application of MSA to other power system issues, such as the network reconfiguration problem, is still a concern [4]. The exploration of the WOA was not effective during the search process [5]. The system failed to maintain the optimal load balance when the load balancing index was high [7]. In high-dimensional space, PSO easily falls into the local optimum and has a very low convergence rate [21]. The reactive and real power loss has increased at a certain DG size [22]. The major limitation of the Grey Wolf Optimizer was its low capability of handling the difficulties of a multi-modal search landscape [23]. The SPEA method doesn't consider the weighted sum of objective functions, which caused unequal optimization objectives [24]. The performance of ACSA was lower when compared with other algorithms [25]. 
The existing methods were successfully implemented for network reconfiguration to reduce power losses and improve the voltage profile. However, simultaneous network reconfiguration with DG placement is not taken into account. There is the need of the hybrid algorithm for solving optimization problems which have better performance, flexibility, and robust. Accordingly, in this research, a BPSOALO hybrid algorithm was implemented to obtain the best configuration and optimum allocation of DG units. This hybrid BPSO-ALO method enhances the voltage profile and minimizes power losses. Four different cases of the system with only reconfiguration, the system with the installation of a single DG unit, the system with reconfiguration and a single DG unit, and the system with reconfiguration and multiple DG units are considered to assess the performance of the hybrid BPSO-ALO method and it is validated by the IEEE 33-bus test system.

\section{Methodology}

\subsection{Objective function}

The loss minimization formulation utilizes an objective function which is shown in Equation 1.

$f=\sum_{i=1}^{n} r_{i} \frac{P_{i}{ }^{2}+Q_{i}{ }^{2}}{\left|V_{i}\right|^{2}}$

Where $\mathrm{n}$ specifies the total number of branches, while $r_{i}, v_{i}, P_{i}, Q_{i}$ designates resistance, voltage, active and reactive power of branch $i$, respectively.

Subject to the following constraints,

$V_{\text {min }} \leq V_{i} \leq V_{\max }$

where $V_{\min }$ and $V_{\max }$ are the minimum and maximum voltage limits of $i^{\text {th }}$ bus

Active power generation limits:

$P D G_{\min } \leq P D G i \leq P D G_{\max }$

Reactive power generation limits:

$\mathrm{QDG}_{\min } \leq Q D G i \leq Q D G_{\max }$

\subsection{Sensitivity analysis}

The placement of DG units for candidate nodes was determined using the Loss Sensitivity Factor. This sensitive node estimation was used to minimize the search space. The load flow for all distribution system lines is used to calculate the LSF, which is organized in descending order. The buses follow the same order for DG installation. Let, the Kth line has impedance $\mathrm{R}_{\mathrm{k}}+\mathrm{J} \mathrm{X}_{\mathrm{k}}$ between $\mathrm{k}-1$ and $\mathrm{k}$ buses and is connected to the load $\mathrm{P}_{\text {eff }}+\mathrm{jQ}$ eff.

Real power loss for line $\mathrm{k}$ is given in Equation 2.

$$
P_{\text {lineloss }}=\frac{\left(P_{e f f}^{2}+Q_{e f f}^{2}\right) R_{k}}{V_{k}^{2}}
$$

The sensitivity factor of real power loss is given in Equation 3.

$$
\frac{\partial P_{\text {lineloss }}}{\partial P_{\text {eff }}}=\frac{2 * P_{\text {eff }} * R_{k}}{V_{k}^{2}}
$$

Where $R_{K}$ represents the resistance of the line k and $V_{k}$ represents the magnitude of the voltage at the receiving end.

\subsection{Binary particle swarm optimization based network reconfiguration}

The BPSO technique was used for finding optimal network reconfiguration which enhances the voltage profile and minimizes power loss. Initialize the particles with a randomly generated population. Find the total possible configurations and, out of all the possible configurations, consider the one which gives a radial configuration. The losses were calculated for all the switching combinations and the configuration which has the lowest power loss is the optimal configuration. In BPSO, the bit string and velocity of the particle were created in the range of $[0,1]$. The velocity of the particle is defined as the possibility of obtaining a value of 1 .

The $\mathrm{X}_{\mathrm{k}}^{\mathrm{i}}$ and $\mathrm{V}_{\mathrm{k}}^{\mathrm{i}}$ represent the particle's position and the velocity at $\mathrm{K}^{\text {th }}$ iteration respectively. Equation 4 is used to calculate the velocity of the $\mathrm{i}^{\text {th }}$ particle at iteration $\mathrm{k}+1$.

$$
\mathrm{V}_{\mathrm{k}+1}^{\mathrm{i}}=\omega \cdot \mathrm{V}_{\mathrm{k}}^{\mathrm{i}}+\mathrm{C}_{1} \mathrm{R}_{1}\left(\mathrm{P}_{\text {best }}-\mathrm{X}_{\mathrm{k}}^{\mathrm{i}}\right)-\mathrm{C}_{2} \mathrm{R}_{2}\left(\mathrm{G}_{\text {best }}-\mathrm{X}_{\mathrm{k}}^{\mathrm{i}}\right)
$$

Where the random values are represented as $R_{1}$ and $R_{2}$; the training coefficients are represented as $\mathrm{C}_{1}$ and $\mathrm{C}_{2}$; the inertia weight factor is represented as $\omega$ that is expressed in Equation 5.

$$
\omega=\omega_{\max }-\left\{\left(\omega_{\max }-\omega_{\min }\right)-\mathrm{k}_{\max }\right\} \times \mathrm{k}
$$

Where the maximum amount of iteration considered for this BPSO is $\mathrm{k}_{\max }$. The position of the particle is updated by adding the prior position and current velocity value. Equation 6 shows the position update of the particles.

$\mathrm{X}_{\mathrm{k}+1}^{\mathrm{i}}=\mathrm{X}_{\mathrm{k}}^{\mathrm{i}}+\mathrm{V}_{\mathrm{k}+1}^{\mathrm{i}}$

The swarm expression of particles remained unchanged in BPSO. The logistic transformation $S\left(V_{k}^{i}\right)$ is utilized for accomplishing this modification as shown in Equation 7 and 8.

$\mathrm{S}\left(\mathrm{V}_{\mathrm{k}+1}^{\mathrm{i}}\right)=\operatorname{sig} \bmod \mathrm{e}\left(\mathrm{V}_{\mathrm{k}+1}^{\mathrm{i}}\right)=\frac{1}{1+\exp \left(\mathrm{V}_{\mathrm{k}+1}^{\mathrm{i}}\right)}$

If rand $<\mathrm{S}\left(\mathrm{V}_{\mathrm{k}+1}^{\mathrm{i}}\right)$ then: $\mathrm{X}_{\mathrm{k}+1}^{\mathrm{i}}=1$;

Else: $X^{i}{ }_{k+1}=0$;

Where the sigmoid limiting transformation is represented as $S\left(V^{i}{ }_{k}\right)$ and the quasi-random value selected between $[0,1]$ is represented as rand. 
3.4Ant lion optimization-based optimal placement of DG units

Mirjalili [26] proposed ALO algorithm. The random movement of ants, building traps, trapping them in traps, capturing prayers, and re-constructing traps are all part of the ALO algorithm. Here, the ALO technique is implemented to obtain the optimal size of the DG units. The population of DG sizes is randomly generated and power losses are calculated for the generated population. The DG values with the lowest losses are most likely the best solution. Update the Ant Lions location. Calculate losses for the updated population by running load flow. If the estimated losses are lower, replace the best solution with it. The ants' positions are stored at random in the matrix Equation 9:

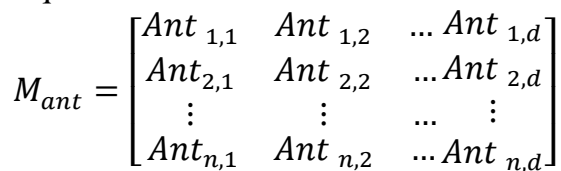

Here, $A n t_{i, j}$ describes the $j^{t h}$ value of $i^{t h}$ variable ant, $\mathrm{n}$ denotes the population size of ants, and d denotes the number of variables. Ant's fitness should be kept within the matrix in terms of the objective function which is given as Equation 10:

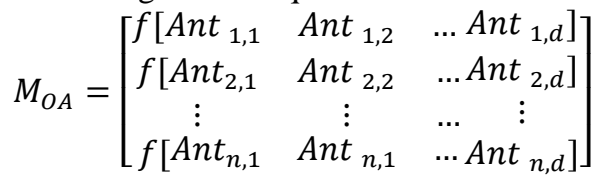

The location and fitness of ant-lion are shown by the matrices $\mathrm{M}_{\text {antlion }}$ and $\mathrm{M}_{\mathrm{OAL}}$, which are given by Equations 11 and 12:

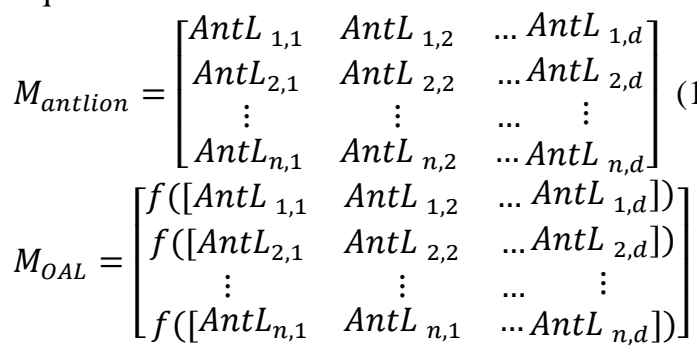

The roulette wheel is utilized to obtain a high probability for the section of ants which is used to detect the optimal ant lion. Equation 13 was used for the process of trapping.

$C_{i}^{t}=$ Antlion $_{j}^{t}+C^{t}$

$d_{i}^{t}=$ Antlion $_{j}^{t}+d^{t}$

Where the minimum and maximum variables in the ant $i$ at iteration $t$ are denoted as $C_{i}^{t}$ and $d_{i}^{t}$ respectively. The location of the chosen ant lion is represented as Antlion $_{j}^{t}$. The ant lion shoots the sand outwards to slide the ant towards the ant lions, which is expressed in Equation 14.

$C^{t}=\frac{C^{t}}{I}$

$D^{t}=\frac{d^{t}}{I}$

where $I=10^{\omega \frac{t}{T}}$; current and the maximum number of iterations are represented as $t$ and $T$ respectively. The ant arrives at the bottom of the pit and is caught by the ant lions during the final stage of the hunting process. Next, the position is updated using Equation 15.

Antlion $_{j}^{t}=$ Ant $_{i}^{t}$ if $f\left(\right.$ Ant $\left._{i}^{t}\right)>f\left(\right.$ Antlion $\left._{j}^{t}\right)$

The best solution is required to be minimized as shown in Equation 16.

$A n t_{i}^{t}=\frac{R_{A}^{t}+R_{E}^{t}}{2}$

Where the random walks selected near the ant lion using a roulette wheel are $R_{A}^{t}$ and $R_{E}^{t}$. The BPSO is used to reconfigure the distribution system and to solve switching operations. The important issue in the distribution system is the selection of the sectionalizing switches. The aforementioned issue lies in two different states, such as the opening or closing of the sectionalizing switches. Here, the opening and closing of switches are specified using the binary values of 0 and 1 respectively. The switching states are decided using a binary vector. The binary vector is used to resolve the problem of reconfiguration of all of the other processes. The result of both active/reactive powers of each DG resource is chosen between the minimum and maximum values as shown in Equation 17 and 18.

$P_{D G, i}^{\min } \leq P_{D g, i} \leq P_{D G, i}^{\max }$

$Q_{G, \min } \leq Q_{G} \leq Q_{G, \max }$

Where the DG's nominal real and phantom power is represented as $P_{D g, i}$, and $Q_{G}$; the minimum range of DG's real and phantom power is represented as $P^{\min }{ }_{D G, i}$ and $Q_{G, \min }$ respectively. Next, the maximum range of DG's real and phantom power is represented as $P_{D G, i}^{\max }$ and $Q_{G, \max }$ respectively. The size assortment of the DG mostly depends on the size (load) of the system and is preselected discretely between $10 \%$ and $80 \%$ of the total system demands.

Figure 1 shows the flow chart of the proposed methodology for network reconfiguration with the installation of DG units. 


\subsection{Algorithm}

Step 1: Read input (line and load data) for IEEE $33-$ Bus test system

Step 2: Initialize the BPSO Parameters. Initialize the particles with a randomly generated population of tie switches.

Step 3: Determine the total number of possible configurations, focusing on those that are radial.

Step 4: Calculate the losses for all the switching combinations.

Step 5: Identify the configuration which has low power loss.

Step 6: Perform load flow for the system.
Step 7: Use the loss sensitivity factor to determine DG locations.

Step 8: Generate the population of DG sizes randomly. Step 9: Calculate power loss for the population.

Step 10: The DG values with the lowest losses are most likely the best solution (elite).

Step 11: Choose the position of the antlion using a roulette wheel. Update the Ant Lions location.

Step 12: Calculate losses for the updated population. Step 13: If the estimated losses are lower, replace the best solution with it; otherwise, return to step 11.

Step 14: If the number of iterations reaches its limit, print the optimal solution.

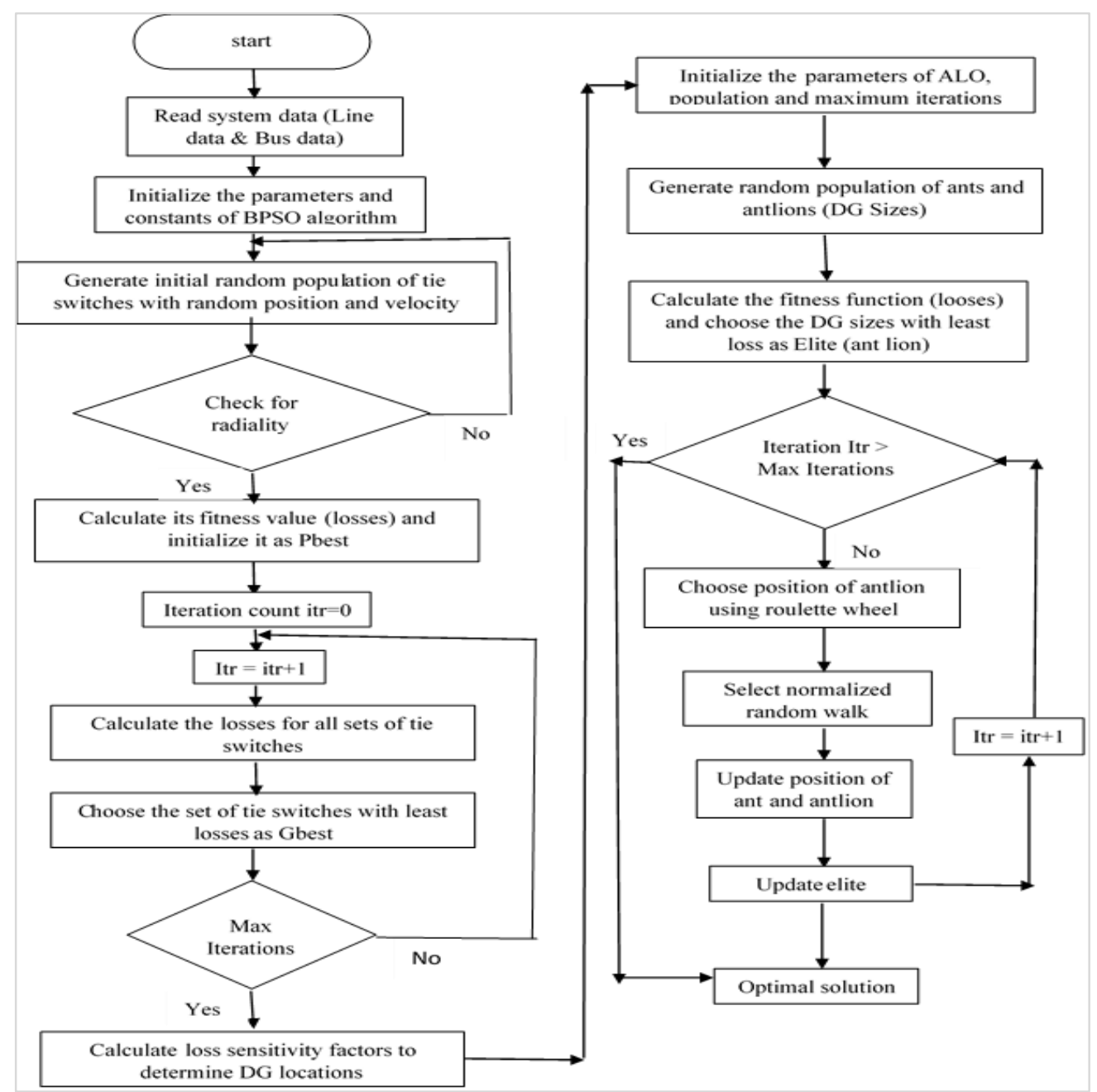

Figure 1 Flow chart of the proposed methodology for network reconfiguration with the installation of DG units

\section{Results}

The hybrid BPSO-ALO approach is implemented on the IEEE 33 bus system with the use of MATLAB programs and executed with a $2.3 \mathrm{GHz}$ and an $8 \mathrm{~GB}$ RAM i-3 processor on a personal computer.
BPSO is mainly used due to its searching efficiency and it eliminates early maturing during the searching process. The results from the hybrid BPSO-ALO method show that the distribution network with DG 
obtains less network loss and supports system voltage while improving the system stability.
The IEEE 33 bus test system structure (base configuration) is shown in Figure 2.

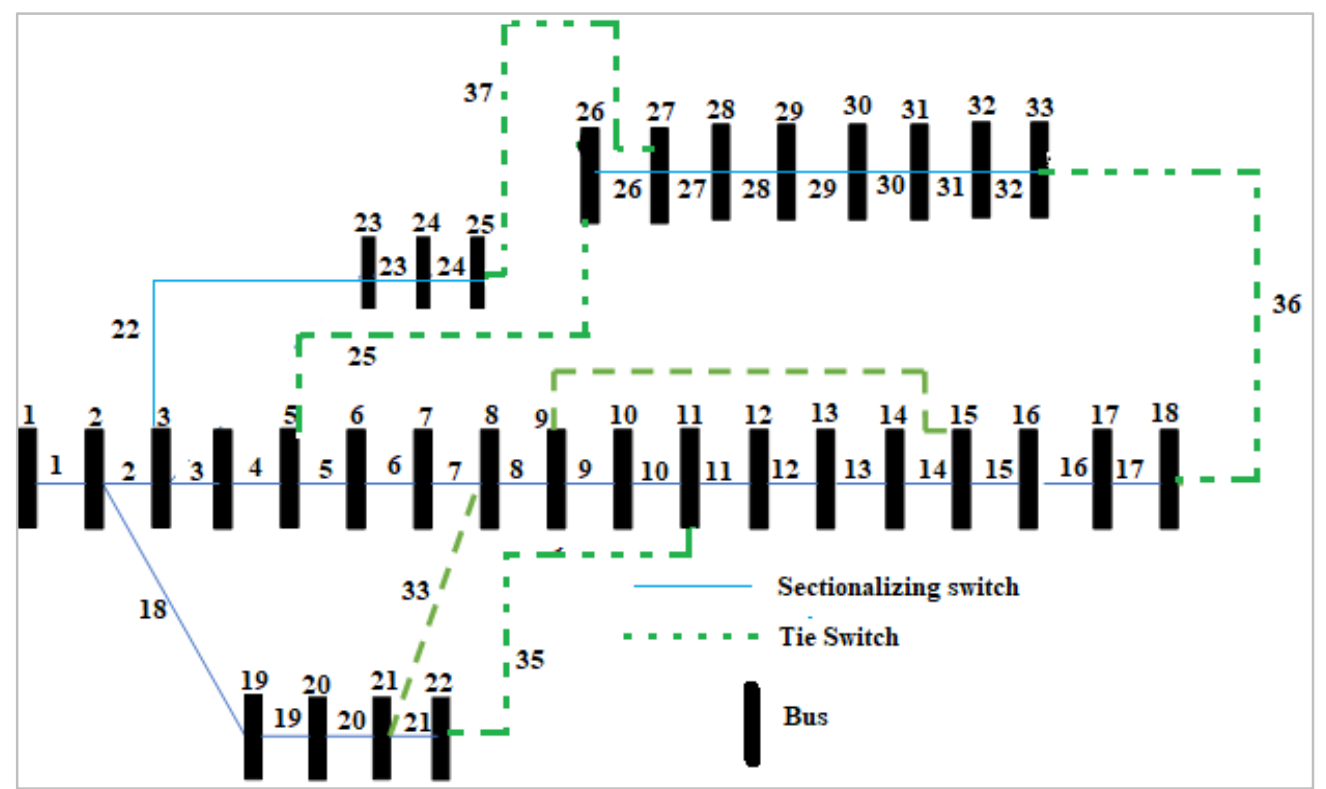

Figure 2 IEEE 33 bus system structure (base configuration)

This IEEE 33 bus system features 32 sectional switches and 5 open switches (tie switches). The test system's cumulative real and reactive loads are 3.72 MW and 2.3 MVAr. The total active power loss for the base configuration is $202.68 \mathrm{~kW}$, and the minimum voltage is 0.910 p.u.

Four cases are examined to validate the performance of the hybrid BPSO-ALO method.

Test case 1: The system with the only reconfiguration. Test case 2: The system has a single DG unit installed. Test Case 3: The bus system is considered with reconfiguration and a single DG unit.

Test case 4: In this case, the bus system with reconfiguration and multiple DG units is considered.
Test case 1: The system with the only reconfiguration

In test case 1, optimal reconfiguration of 33 bus systems is achieved without the integration of DG units. The performance analysis of test case 1 is shown in Table 1. The voltage profile and reconfigured network for test case 1 are depicted in Figures 3 and 4 respectively.

Table 1 shows that the 33-bus system with tie switches $7,9,14,32,37$ has the least power loss, and the minimum voltage is increased from 0.91075 p.u to 0.94621 p.u, as shown in Table 1. The power losses were reduced from $202.68 \mathrm{~kW}$ to $96.1831 \mathrm{~kW}$.

Table 1 Performance analysis of test case 1

\begin{tabular}{lll}
\hline & Base configuration & After reconfiguration \\
\hline Tie switches & $33,34,35,36,37$ & $7,9,14,32,37$ \\
\hline Power losses & $202.68 \mathrm{~kW}$ & $96.1831 \mathrm{~kW}$ \\
\hline Reduction in Power losses & ----------- & $52.5443 \%$ \\
\hline Minimum per unit voltage & 0.91075 & 0.94621 \\
\hline
\end{tabular}




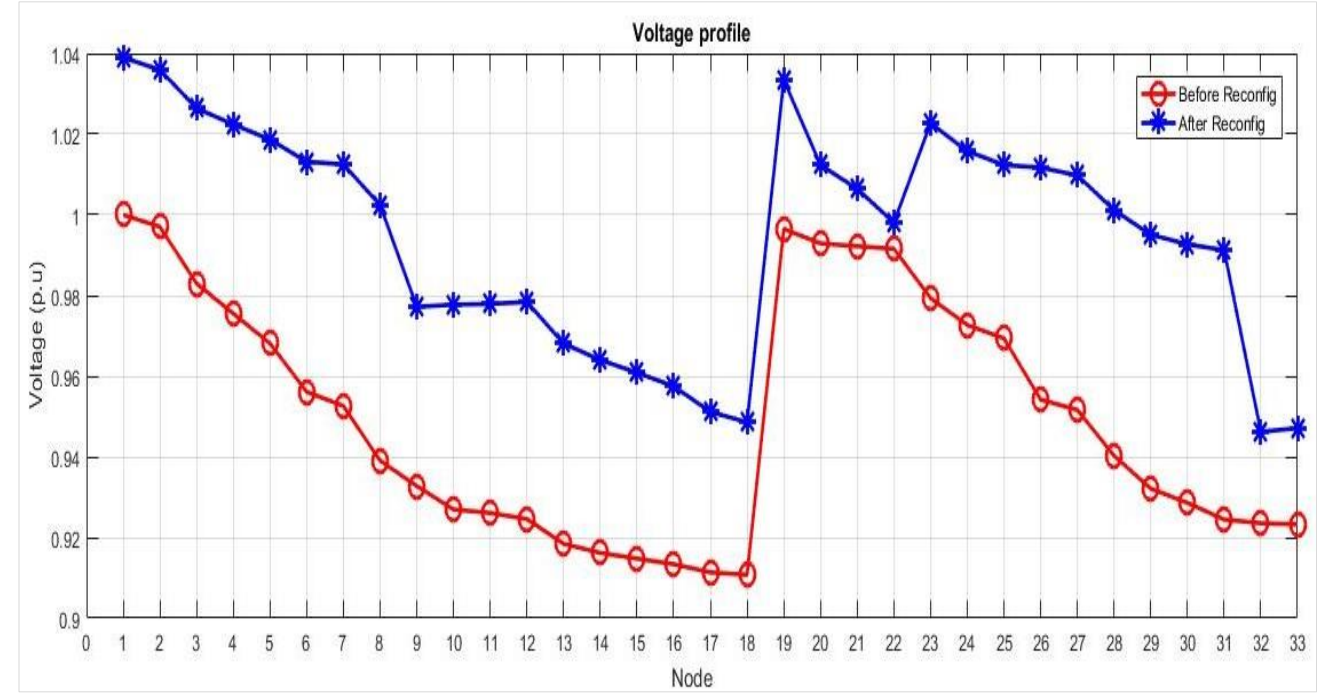

Figure 3 Voltage profile for test case 1

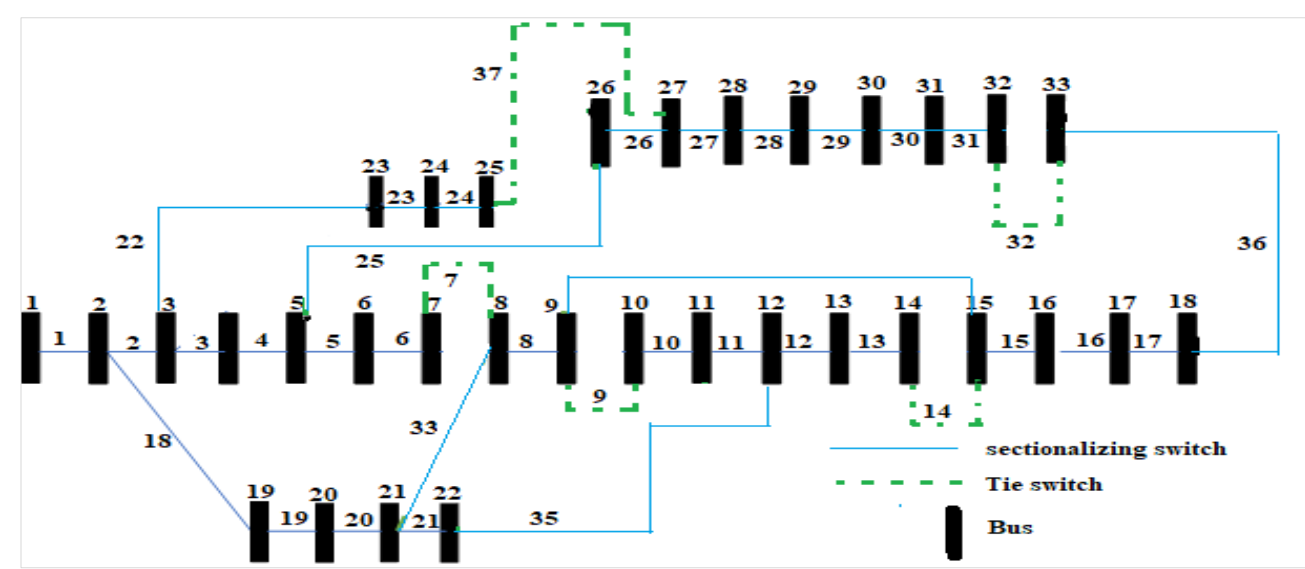

Figure 4 Structure of reconfigured IEEE 33 bus system

Test case 2: The system has a single DG unit installed.

In test case 2, a 2.22 MW DG unit is installed on the base configuration's bus number 27 . The power losses were reduced from $202.68 \mathrm{~kW}$ to $101.168 \mathrm{~kW}$. Table 2 displays the results of test case 2, and Figure 5 depicts the voltage profile.
Table 2 shows that the power loss for the base configuration with a single DG installation is less than the power loss for the base configuration. When a single DG unit of $2.22 \mathrm{MW}$ was installed on bus number 27 , the power loss in the base configuration was decreased from $202.68 \mathrm{~kW}$ to $101.168 \mathrm{~kW}$.

Table 2 Performance analysis of test case 2

\begin{tabular}{lll}
\hline & $\begin{array}{l}\text { Base } \\
\text { configuration }\end{array}$ & Base configuration with single DG installation \\
\hline Tie switches & $33,34,35,36,37$ & $33,34,35,36,37$ \\
\hline Power losses & $202.68 \mathrm{~kW}$ & $101.168 \mathrm{~kW}$ \\
\hline Reduction in Power losses & ----------- & $50.0849 \%$ \\
\hline Size of DG & --------- & $2.22 \mathrm{MW}$ \\
\hline Location of DG & ---------- & 27 \\
\hline
\end{tabular}




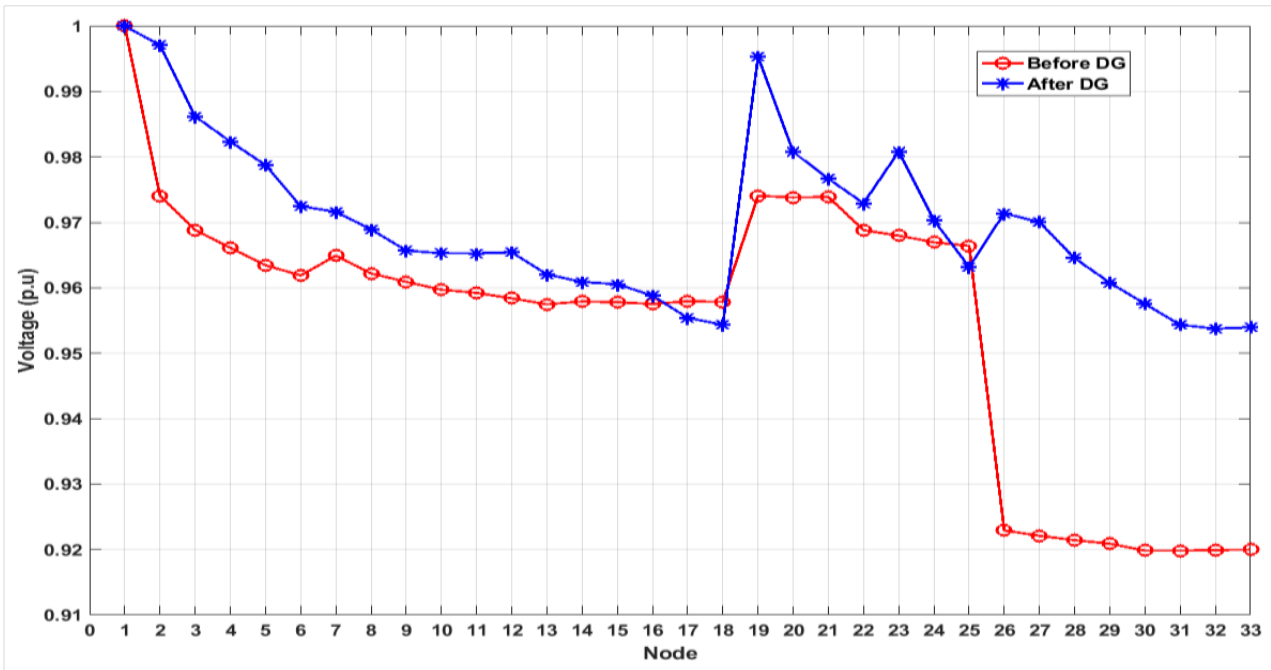

Figure 5 Voltage profile for test case 2

Test Case 3: The bus system is considered with reconfiguration and a single DG unit.

In test case 3, the 33-bus system is carried out by reconfiguration with a single DG unit installation. The optimal reconfiguration is achieved by using the BPSO algorithm. The optimal DG size and location are achieved by using ALO and the loss sensitivity factor. Table 3 displays the results of test case 3 , and
Figure 6 depicts the voltage profile. The reconfigured network with a single DG unit is shown in Figure 7.

Table 3 shows that the 33-bus system with tie switches $7,10,14,37,36$ has the least power loss of $61.997 \mathrm{~kW}$, and the minimum voltage has increased from 0.91075 p.u to 0.95294 p.u.

Table 3 Performance analysis of test case 3

\begin{tabular}{lll}
\hline & Base configuration & $\begin{array}{l}\text { After reconfiguration with single DG } \\
\text { unit }\end{array}$ \\
\hline Tie switches & $33,34,35,36,37$ & $7,10,14,37,36$ \\
\hline Power losses & $202.68 \mathrm{~kW}$ & $61.997 \mathrm{~kW}$ \\
\hline Reduction in Power losses & ------------ & $69.4114 \%$ \\
\hline Minimum per unit voltage: & 0.91075 & 0.95294 \\
\hline Size (location of DG) & ----------- & $1.13 \mathrm{MW}(25)$ \\
\hline
\end{tabular}

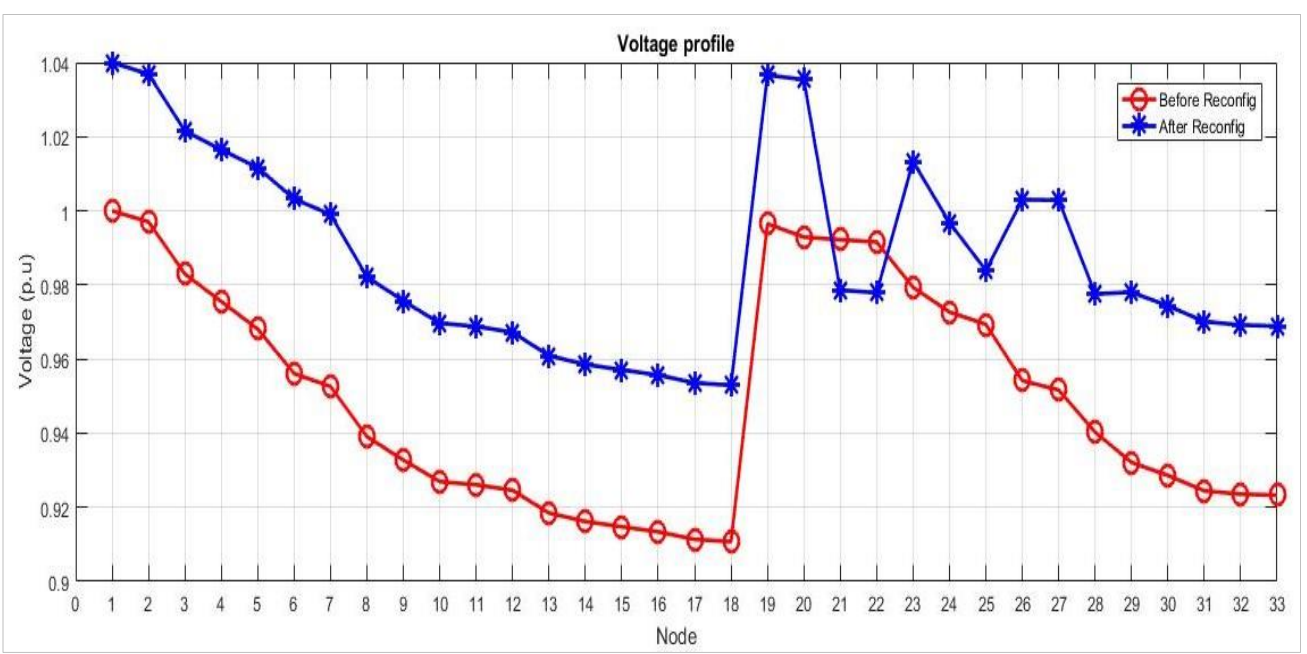

Figure 6 Voltage profile for test case 3 


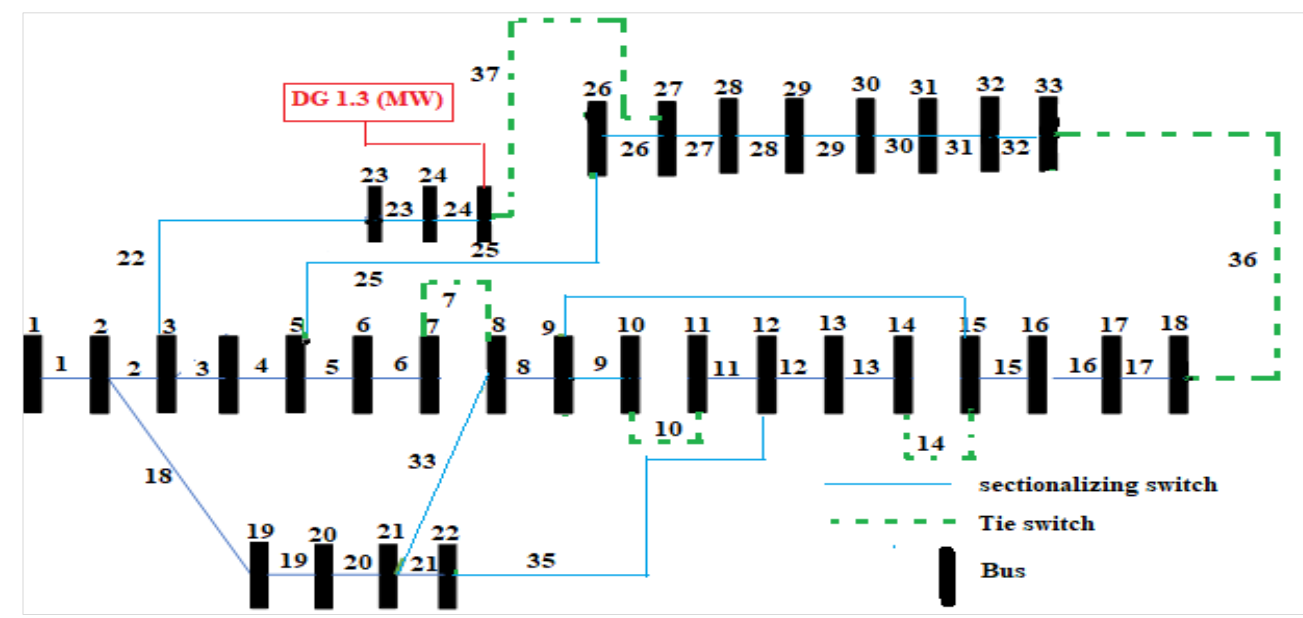

Figure 7 Structure of reconfigured IEEE 33 bus system with single DG unit

Test case 4: In this case, the bus system with reconfiguration and multiple DG units is considered

In test case 4 , the 33-bus system is carried out by reconfiguration with multiple DG units for installation. The optimal reconfiguration is achieved by using the BPSO algorithm. The optimal DG size and location are achieved by using ALO and the loss sensitivity factor. The performance of test case 4 is displayed in Table 4 and the voltage profile for test case 4 is depicted in Figure 8 and the reconfigured network with multiple DG units is depicted in Figure 9.

Table 4 shows that the 33-bus system with tie switches $7,14,11,32,28$ has the least power loss of $45.71 \mathrm{~kW}$, and the minimum voltage has increased from 0.91075 p.u. to 0.9812 p.u.

Table 5 shows the comparison of the proposed methodology with MSSOE [2], ALO [3], SPEA [24], and ACSA [25].

Table 4 Performance analysis of test case 4

\begin{tabular}{lll}
\hline & Base configuration & After reconfiguration with multiple DG units \\
\hline Tie switches & $33,34,35,36,37$ & $7,14,11,32,28$ \\
\hline Power losses & $202.68 \mathrm{~kW}$ & $45.71 \mathrm{~kW}$ \\
\hline Reduction in Power losses & ---------- & $77.4472 \%$ \\
\hline Minimum per unit voltage: & 0.91075 & 0.9812 \\
\hline Size (location of DG) & ----------- & $1.1368(21), 1.4647(33)$, \\
& & $0.8199(29)$ \\
\hline
\end{tabular}

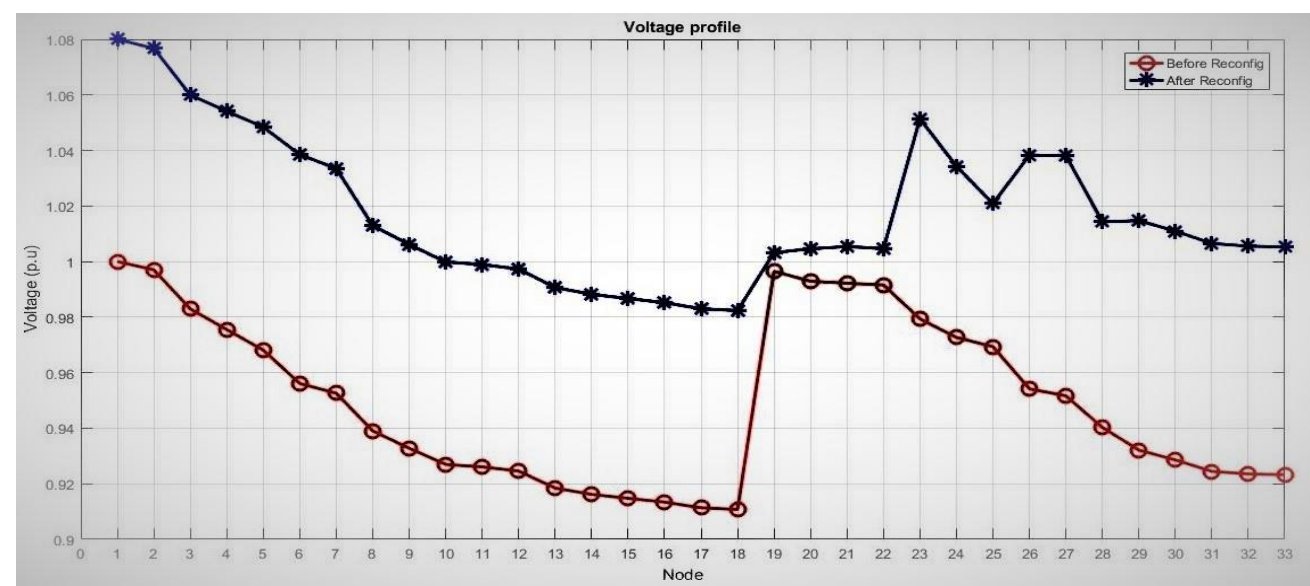

Figure 8 Voltage profile for test case 4 


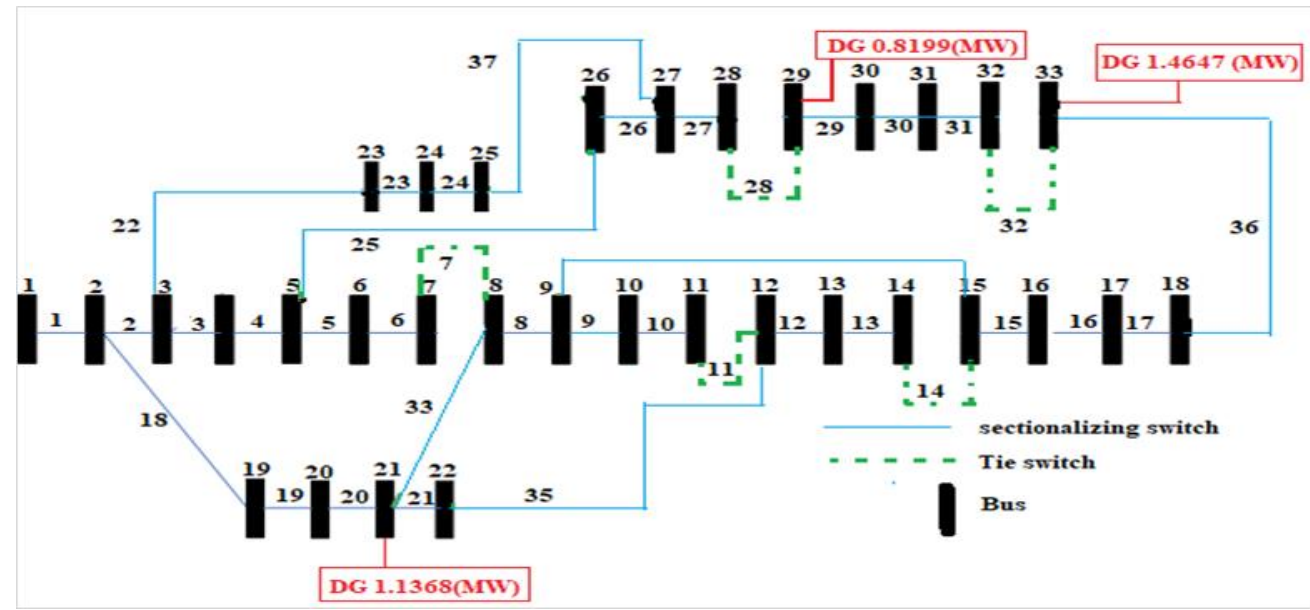

Figure 9 Structure of reconfigured network with multiple DG units

Table 5 Comparative analysis of hybrid BPSO-ALO methodology

\begin{tabular}{|c|c|c|c|c|c|c|}
\hline Test case & Item & $\begin{array}{l}\text { Modified } \\
\text { sequential } \\
\text { switch } \\
\text { opening } \\
\text { and } \\
\text { exchange } \\
{[2]}\end{array}$ & $\begin{array}{l}\text { ALO } \\
\text { algorithm [3] }\end{array}$ & $\begin{array}{l}\text { Strength } \\
\text { pareto } \\
\text { evolutionary } \\
\text { algorithm [24] }\end{array}$ & $\begin{array}{l}\text { Adaptive cuckoo } \\
\text { search algorithm } \\
{[25]}\end{array}$ & $\begin{array}{l}\text { Hybrid BPSO- } \\
\text { ALO method }\end{array}$ \\
\hline \multirow[t]{4}{*}{$\begin{array}{l}\text { I (Only } \\
\text { Reconfiguration) }\end{array}$} & $\begin{array}{l}\text { Tie switches } \\
\text { opened }\end{array}$ & $7,9,14,32,37$ & $7,9,14,32,37$ & \multirow{4}{*}{ NA } & $7,14,9,32,28$ & $7,9,14,32,37$ \\
\hline & $\begin{array}{l}\text { Power loss } \\
(\mathrm{kW})\end{array}$ & 139.55 & 139.55 & & 139.98 & 96.1831 \\
\hline & $\begin{array}{l}\% \\
\text { Reduction } \\
\text { of Power } \\
\text { loss }\end{array}$ & 31.1 & 31.1 & & 30.93 & 52.5443 \\
\hline & $\begin{array}{l}\text { Min voltage } \\
\text { (p.u.) }\end{array}$ & 0.9378 & 0.9378 & & 0.9413 & 0.94621 \\
\hline \multirow[t]{4}{*}{$\begin{array}{l}\text { II (Single DG unit } \\
\text { Installation) }\end{array}$} & $\begin{array}{l}\text { Tie switches } \\
\text { opened }\end{array}$ & \multirow{4}{*}{ NA } & \multirow{4}{*}{ NA } & $33,34,35,36,37$ & \multirow{4}{*}{ NA } & $33,34,35,36,37$ \\
\hline & $\begin{array}{l}\begin{array}{l}\text { Power loss } \\
(\mathrm{kW})\end{array} \\
\end{array}$ & & & 105.63 & & 101.168 \\
\hline & $\begin{array}{l}\% \\
\text { Reduction } \\
\text { of Power } \\
\text { loss }\end{array}$ & & & 47.88 & & 50.0849 \\
\hline & $\begin{array}{l}\text { DG size } \\
(\mathrm{MW}) \text { and } \\
\text { bus number }\end{array}$ & & & $2.229(6)$ & & $2.22(27)$ \\
\hline \multirow{4}{*}{$\begin{array}{l}\text { III } \\
\text { (Reconfiguration } \\
\text { with single DG } \\
\text { unit installation) }\end{array}$} & $\begin{array}{l}\text { Tie switches } \\
\text { opened }\end{array}$ & \multirow{4}{*}{ NA } & \multirow{4}{*}{ NA } & $9,14,27,33,34$ & \multirow{4}{*}{ NA } & $7,10,14,37,36$ \\
\hline & $\begin{array}{l}\text { Power loss } \\
(\mathrm{kW})\end{array}$ & & & 80.59 & & 61.997 \\
\hline & $\begin{array}{l}\% \\
\text { Reduction } \\
\text { of Power } \\
\text { loss }\end{array}$ & & & 60.23 & & 69.4114 \\
\hline & $\begin{array}{l}\text { DG size } \\
(\mathrm{MW}) \text { and } \\
\text { bus number }\end{array}$ & & & $1.93(29)$ & & $1.13(25)$ \\
\hline
\end{tabular}




\begin{tabular}{|c|c|c|c|c|c|c|}
\hline Test case & Item & $\begin{array}{l}\text { Modified } \\
\text { sequential } \\
\text { switch } \\
\text { opening } \\
\text { and } \\
\text { exchange } \\
\text { [2] }\end{array}$ & $\begin{array}{l}\text { ALO } \\
\text { algorithm [3] }\end{array}$ & $\begin{array}{l}\text { Strength } \\
\text { pareto } \\
\text { evolutionary } \\
\text { algorithm [24] }\end{array}$ & $\begin{array}{l}\text { Adaptive cuckoo } \\
\text { search algorithm } \\
{[25]}\end{array}$ & $\begin{array}{l}\text { Hybrid BPSO- } \\
\text { ALO method }\end{array}$ \\
\hline \multirow{6}{*}{$\begin{array}{l}\text { IV } \\
\text { (Reconfiguration } \\
\text { with multiple DG } \\
\text { unit's installation) }\end{array}$} & $\begin{array}{l}\text { Tie switches } \\
\text { opened }\end{array}$ & $\begin{array}{l}7,9,27,34, \\
36\end{array}$ & $7,11,28,32$ & $11,27,30,33,34$ & $33,34,11,31,28$ & $7,14,11,32,28$ \\
\hline & $\begin{array}{ll}\text { Power loss } \\
(\mathrm{kW})\end{array}$ & 57.7 & 58.34 & 58.55 & 53.21 & 45.71 \\
\hline & $\begin{array}{l}\% \\
\text { Reduction }\end{array}$ & 71.53 & 71.21 & 71.11 & 73.75 & 77.4472 \\
\hline & $\begin{array}{l}\text { of Power } \\
\text { loss }\end{array}$ & & & & & \\
\hline & $\begin{array}{l}\text { Min voltage } \\
\text { (p.u.) }\end{array}$ & 0.9774 & 0.96910 & NA & 0.9806 & 0.9812 \\
\hline & $\begin{array}{l}\text { DG size } \\
(\mathrm{MW}) \text { and } \\
\text { bus number }\end{array}$ & $\begin{array}{l}0.754(14) \\
1.099(24) \\
1.071(30)\end{array}$ & $\begin{array}{l}0.947236 \quad(9) \\
0.548419(24) \\
1.00873(30)\end{array}$ & $\begin{array}{l}0.6910(18) \\
0.7334 \quad(29), \\
0.7429(8)\end{array}$ & $\begin{array}{ll}0.8968 & (18), \\
1.4381 & (25), \\
0.9646(7) & \end{array}$ & $\begin{array}{l}1.1368(21) \\
1.4647(33) \\
0.8199(29)\end{array}$ \\
\hline
\end{tabular}

The power losses in the network are reduced by implementing the hybrid BPSO-ALO methodology when compared with the Modified Sequential Switch Opening and Exchange [2], ALO Algorithm [3], SPEA [24], and ACSA [25]. The comparison shows that the hybrid BPSO-ALO method achieves better performance in terms of minimization of power loss and enhancement in voltage profile in all the scenarios.

\section{Discussion}

Table 1 demonstrates that the best reconfiguration is to operate the tie switches $7,9,14,32,37$. The power loss has been reduced from $202.68 \mathrm{~kW}$ to $139.98 \mathrm{~kW}$. The minimum voltage per unit has risen from 0.91075 to 0.94621 . Table 2 indicates that when a single DG unit of $2.22 \mathrm{MW}$ was installed on bus number 27 , the power loss in the base configuration was decreased from $202.68 \mathrm{~kW}$ to $101.168 \mathrm{~kW}$. Table 3 demonstrates that the best reconfiguration in test scenario 3 is to operate the tie switches 7,10,14,37,36. When compared to the base configuration, the power loss with simultaneous reconfiguration with the installation of a single DG unit was reduced from $202.68 \mathrm{~kW}$ to $61.997 \mathrm{~kW}$. The minimum voltage per unit has risen from 0.91075 to 0.95294 . Table 4 demonstrates that the best reconfiguration in test scenario 4 is to operate the tie switches 7,14,11,32,28. In this case, the power loss was decreased from 202.68 $\mathrm{kW}$ to $45.71 \mathrm{~kW}$ when simultaneous reconfiguration was done with the installation of multiple DG units. The minimum voltage per unit has risen from 0.91075 to 0.9812 . The optimal DG sizes are $1.1368 \mathrm{MW}$, $1.4647 \mathrm{MW}$, and $0.8199 \mathrm{MW}$, which are placed on bus numbers 21, 33, and 29. The suggested technique 1030 outperforms traditional methods. In terms of decreased power loss and enhanced voltage profile, Test Case IV (i.e., network reconfiguration with multiple DG units) outperforms the base configuration.

By applying the hybrid BPSO-ALO approach, the power loss in the IEEE 33 test bus system is decreased to $45.71 \mathrm{~kW}$ for case IV, which is smaller than MSSO $57.7 \mathrm{~kW}$, ALO $58.34 \mathrm{~kW}$, SPEA $58.55 \mathrm{~kW}$, and ACSA $53.21 \mathrm{~kW}$. A complete list of abbreviations is shown in Appendix $I$.

\subsection{Limitations}

The reduction of reactive and apparent power losses using network reconfiguration was not discussed in this work. The time sequence variation in renewable DGs and loads was not taken into account in the proposed method.

\section{Conclusion and future work}

In this research work, the hybrid BPSO-ALO technique is used to obtain the optimum network reconfiguration along with DG installation. The hybrid BPSO-ALO technique considers 4 different cases during reconfiguration and DG placement to validate the performance. The hybrid BPSO-ALO technique is implemented on the IEEE 33-bus test system and the obtained results show that case IV (Multiple DG unit installation with network reconfiguration) has better performance in terms of reduced power loss and enhanced voltage profile. The power loss for case IV is $45.71 \mathrm{~kW}$, which is less when compared to MSSO, ALO, SPEA, and ACSA. In the future, the work could be extended to implementation on the IEEE 69 and 
119 bus systems to reduce active power loss, operating costs, and emissions of polluting gases.

\section{Acknowledgment}

The authors appreciate the support and encouragement they received from the Vignana Bharathi Institute of Technology in Hyderabad and the Sreenidhi Institute of Science and Technology in Hyderabad. The authors thank the Department of Science and Technology for providing computational resources through the FIST program at Vignana Bharathi Institute of Technology in Hyderabad, where the computational work is completed.

\section{Conflicts of interest}

The authors have no conflicts of interest to declare.

\section{References}

[1] Ali A, Keerio MU, Laghari JA. Optimal site and size of distributed generation allocation in radial distribution network using multi-objective optimization. Journal of Modern Power Systems and Clean Energy. 2020; 9(2):404-15.

[2] Vai V, Suk S, Lorm R, Chhlonh C, Eng S, Bun L. Optimal reconfiguration in distribution systems with distributed generations based on modified sequential switch opening and exchange. Applied Sciences. 2021; 11(5):1-13.

[3] Vijayalaksmi N, Gayathri K. Distribution system reconfiguration and $\mathrm{dg}$ allocation for power loss minimization and voltage profile enhancement using ALO algorithm. Open Access. JCR. 2020; 7(14): 386781.

[4] Nguyen TT, Long DT. Network reconfiguration for minimizing power loss by moth swarm algorithm. International Journal of Advanced Computer Science and Applications. 2020; 11(7):33-9.

[5] Tiwari RK, Babu PR. Optimal reconfiguration of electrical distribution system by whale optimization algorithm. International Journal of Recent Technology and Engineering. 2019; 8(3):2392-8.

[6] Kamble SG, Vadirajacharya K, Patil UV. Distribution system reconfiguration for loss minimization and voltage profile enhancement by using discrete improved binary particle swarm optimization algorithm. International Journal of Recent Technology and Engineering. 2019; 8(2S11):900-6.

[7] Babu PR, Kiran RYS, Lakshmi SS, Sree PR, Reddy MK. Distribution system reconfiguration for improvement in load balance and service restoration using artificial ant colony optimization. Pramana Research Journal.2019; 9(5):29-36.

[8] Pyone LS. Feeder reconfiguration and distributed generator placement in electric power distribution network. American Journal of Electrical and Computer Engineering. 2018; 2(2):56-63.

[9] Thummala RK, Rao GK. Reconfiguration of the distribution system and optimal dg placement DG to enhance voltage profile and reduce losses. International Journal of Engineering \& Technology. 2018; 7(2):348.

1031
[10] Sandhya K, Vemulapati VS. Active power loss minimization using simultaneous network reconfiguration and DG placement with AGPSO algorithm. International Journal for Research in Applied Science \& Engineering Technology. 2015; 3(8):156-63.

[11] Ben HI, Salah SB, Msahli F, Mimouni MF. Optimal integration of distributed generations with network reconfiguration using a pareto algorithm. International Journal of Renewable Energy Research. 2018; 8(1):345-56.

[12] Anjali G, Chidanandappa R, Ananthapadmanabha T. Network reconfiguration of radial distribution network with DG using cuckoo search algorithm. International Journal of Innovative Research in Computer and Communication Engineering. 2017; 5(6):11177-85.

[13] Kumar GS, Kumar SS, Kumar SJ. Reconfiguration of radial distribution system for loss reduction and reliability enhancement with DG placement. International Journal of Applied Engineering Research. 2018; 13(23):16356-62.

[14] Hung DQ, Mithulananthan N, Lee KY. Optimal placement of dispatchable and nondispatchable renewable DG units in distribution networks for minimizing energy loss. International Journal of Electrical Power \& Energy Systems. 2014; 55:179-86.

[15] Georgilakis PS, Hatziargyriou ND. Optimal distributed generation placement in power distribution networks: models, methods, and future research. IEEE Transactions on Power Systems. 2013; 28(3):3420-8.

[16] Chithradevi SA, Lakshminarasimman L, Balamurugan R. Stud krill herd algorithm for multiple DG placement and sizing in a radial distribution system. Engineering Science and Technology, an International Journal. 2017; 20(2):748-59.

[17] Murty VV, Kumar A. Optimal placement of DG in radial distribution systems based on new voltage stability index under load growth. International Journal of Electrical Power \& Energy Systems. 2015; 69:24656.

[18] Reddy PD, Reddy VV, Manohar TG. Application of flower pollination algorithm for optimal placement and sizing of distributed generation in distribution systems. Journal of Electrical Systems and Information Technology. 2016; 3(1):14-22.

[19] Prabha DR, Jayabarathi T. Optimal placement and sizing of multiple distributed generating units in distribution networks by invasive weed optimization algorithm. Ain Shams Engineering Journal. 2016; 7(2):683-94.

[20] Ameli A, Bahrami S, Khazaeli F, Haghifam MR. A multiobjective particle swarm optimization for sizing and placement of DGs from DG owner's and distribution company's viewpoints. IEEE Transactions on Power Delivery. 2014; 29(4):1831-40.

[21] Prakash DB, Lakshminarayana C. Multiple DG placements in distribution system for power loss reduction using PSO algorithm. Procedia Technology. 2016; 25:785-92. 
[22] Singh B, Gyanish BJ. Impact assessment of DG in distribution systems from minimization of total real power loss viewpoint by using optimal power flow algorithms. Energy Reports. 2018; 4:407-17.

[23] Sanjay R, Jayabarathi T, Raghunathan T, Ramesh V, Mithulananthan N. Optimal allocation of distributed generation using hybrid grey wolf optimizer. IEEE Access. 2017; 5:14807-18.

[24] Hamida IB, Salah SB, Msahli F, Mimouni MF. Optimal network reconfiguration and renewable DG integration considering time sequence variation in load and DGs. Renewable Energy. 2018; 121:66-80.

[25] Nguyen TT, Truong AV, Phung TA. A novel method based on adaptive cuckoo search for optimal network reconfiguration and distributed generation allocation in distribution network. International Journal of Electrical Power \& Energy Systems. 2016; 78:801-15.

[26] Mirjalili S. The ant lion optimizer. Advances in Engineering Software. 2015; 83:80-98.

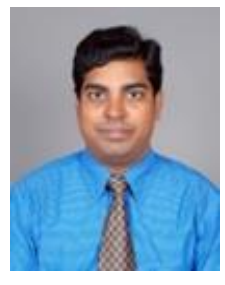

G. Poornachandra Rao is an Associate Professor at Vignana Bharathi Institute of Technology's Electrical and Electronics Engineering Department. He earned his B.Tech. from Chittoor's Sreenivasa Institute of Technology and Management Studies. The Sreenidhi Institute of Science and Technology, Hyderabad, awarded him an M.Tech. At Visvesvaraya Technological University in Belagavi. He is currently pursuing a Ph.D. in Electrical Engineering. Distribution Systems, Power Systems, and Distribution Automation are his areas of interest. He is a life member of the Institution of Electronics and Telecommunication Engineers (IETE) and the Indian Society for Technical Education (ISTE). He has 13 years of teaching experience and has ten papers published in peer-reviewed journals.

Email: g.poornachandrarao@gmail.com

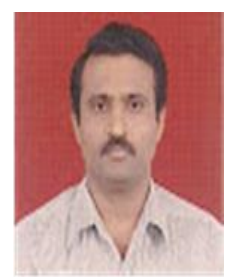

Dr. P. Ravi Babu is a professor at the Sreenidhi Institute of Science and Technology's Department of Electrical and Electronics Engineering. In 2010, he obtained his Ph.D. from JNTU in Hyderabad, Andhra Pradesh, India. He graduated from the University of Mysore in Karnataka, India, with a B.E. in Electrical and Electronics Engineering in 1996 and an M. Tech in Power Systems in 1999. He has been teaching for 21 years and has 115 technical papers published in international journals and conferences. Demand Side Management in power systems, as well as Energy Conservation Studies on home and industrial loads, are among his current research interests. Minimization of losses in electrical distribution systems, Fuzzy logic, Ant colony algorithms, Shipboard Reconfiguration, Genetic Algorithms, and Simulated Annealing approaches to Power Systems are some of his main areas of interest.

Email: ravi.dsm@gmail.com

\begin{tabular}{|c|c|c|}
\hline & & \\
\hline S. No. & Abbreviation & Description \\
\hline 1 & AACO & $\begin{array}{lll}\text { Artificial } & \text { Ant } & \text { Colony } \\
\text { Optimization } & & \\
\end{array}$ \\
\hline 2 & ACSA & $\begin{array}{lll}\begin{array}{l}\text { Adaptive } \\
\text { Algorithm }\end{array} & \text { Cuckoo } & \text { Search } \\
\end{array}$ \\
\hline 3 & ALO & Ant Lion Optimizer \\
\hline 4 & BPSO & $\begin{array}{ll}\text { Binary Particle } & \text { Swarm } \\
\text { Optimization } & \end{array}$ \\
\hline 5 & BPSO-ALO & $\begin{array}{lllr}\text { Binary } & \text { Particle } & & \text { Swarm } \\
\text { Optimization } & \text { with } & \text { Ant } & \text { Lion } \\
\text { Optimizer } & & & \\
\end{array}$ \\
\hline 6 & DG & Distributed Generation \\
\hline 7 & HGWO & Hybrid Grey Wolf Optimizer \\
\hline 8 & I-DBEA & $\begin{array}{l}\text { Improved Decomposition Based } \\
\text { Evolutionary Algorithm }\end{array}$ \\
\hline 9 & LSF & Loss Sensitivity Factor \\
\hline 10 & MSA & Moth Swarm Algorithm \\
\hline 11 & MSSO & $\begin{array}{l}\text { Modified Sequential } \\
\text { Opening }\end{array}$ \\
\hline 12 & MSSOE & $\begin{array}{l}\text { Modified Sequential Switch } \\
\text { Opening and Exchange }\end{array}$ \\
\hline 13 & $\mathrm{PSO}$ & Particle Swarm Optimization \\
\hline 14 & SPEA & $\begin{array}{l}\text { Strength Pareto Evolutionary } \\
\text { Algorithm }\end{array}$ \\
\hline 15 & WOA & Whale Optimization Algorithm \\
\hline
\end{tabular}

